\title{
The frequencies and functions of discourse markers in the Iranian university EFL classroom discourse
}

Nejadansari, Dariush

University of Isfahan, Iran (nejadansari@gmail.com)

Mohammadi, Ali Mohamad $\measuredangle$

University of Isfahan, Iran (a-mohammadi@araku.ac.ir)

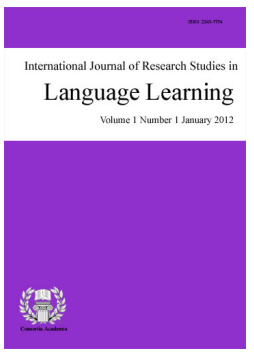

ISSN: 2243-7754 Online ISSN: 2243-7762

OPEN ACCESS

\section{Abstract}

Classroom discourse is the investigation of the models of classroom participation and is a comprehensive and multidimensional phenomenon. As semantically empty and functionally complicated linguistic devices, discourse markers assist the teachers and the learners monitor their discourse in the classroom. This exploratory study analyzed the frequency of occurrence, distribution, and the pragmatic functions of DMs in the Iranian university EFL teachers' and learners' classroom discourse quantitatively and qualitatively. Applying Fraser (1999, 2008) taxonomy, the researchers explored the frequency of occurrence and distribution of discourse markers quantitatively. The qualitative phase researched the functions of DMs on the basis of Brinton's (1996) classification. The data was recorded and transcribed from four EFL teachers' and students' classroom interactions. The results revealed that the subjects applied few DMs $-7.76 \%$ out of the whole lexical size; overemployed message relating DMs; underused focus and attention markers; and never used comment and attitude markers. Also, in the process of monitoring discourse, teachers utilized more than $60 \%$ of DMs and their gender played no significant part. Moreover, the subjects applied textual functions more frequently than interpersonal functions, overusing information indicators and underusing closing and turn giving markers. The insufficient and imbalanced use of DMs and their relevant functions provide the evidence for the typical neglect of the knowledge of these discourse managing and regulating devices as an educational reality due to the inadequate input for discourse pedagogy in the Iranian university EFL context. This study can have some pedagogical implications for curriculum designers, teachers, learners, teacher trainers, and materials developers.

Keywords: classroom discourse; frequencies; functions; discourse markers 


\section{The frequencies and functions of discourse markers in the Iranian university EFL classroom discourse}

\section{Introduction}

Discourse analysis is the study of language in use and classroom discourse analysis is the study of the patterns of participation in the classroom on the basis of the analysis of turn-taking, topic analysis, and task analysis, concerning the different aspects of classroom tasks (Walsh, 2006). One component of classroom discourse is the employment of linguistic elements known as discourse markers (henceforth DMs) by the teacher and the students in the classroom situation. DMs are elements associating units of talks (Schiffrin, 1987), pragmatic classes signaling discourse segments, (Fraser, 1999), and context specific components facilitating speech interpretation (Aijmer, 2002). Why should we analyze DMs? They provide information regarding the way speakers and hearers jointly integrate forms, meanings, and actions to make a comprehensive sense out of what is said in the process of communication. In this process the emergence of discourse coherence is based on the proper and well-functioned application of DMs. So the study of the way DMs create and display relationships between speech units, linguistically and functionally, would provide important guidelines concerning how texts are produced, re-expressed, reformulated, distributed, and consumed in social contexts such as EFL classrooms (Schiffrin, 1987).

The assumption of this study is that the application of discourse markers is indispensable in texts, signals effective communication in discourse, ensures text coherence, and they are multifunctional. This exploratory study aims to explore and explain how Iranian EFL teachers and learners apply DMs in terms of the occurrences, frequencies, distributions, and functions quantitatively and qualitatively with an analytic, critical, and comparative approach in mind.

The questions researched in this exploratory analysis are:

1. What is the interaction between the frequency and distribution of DMs and the general lexical size in the Iranian university EFL classroom interactions?

2. What is the general category and distribution of DMs in the Iranian FEL classes?

3. What kind of relationship is there between the teachers' and the students' treatment of DMs?

4. To what extent does teachers' gender influence the application of DMs in these classes?

5. What are the type, occurrence, and distribution of DMs in the Iranian university EFL teachers' interactions?

6. What are the type, occurrence, and distribution of DMs in the Iranian university EFL students' interactions?

7. What are the predominant functions of DMs in the Iranian EFL teacher-student classroom interactions?

The subsequent sections will offer theoretical background on the studies carried out, followed by a report on the characteristics of the teachers and students, data collection and analysis instruments and procedures. The article finally ends with results, discussions, conclusions, and the implications. 


\section{Theoretical Background}

Although DMs do not seem complicated, the former investigations reveal that it is not the case. That is why different terminologies, definitions, classifications, and taxonomies are offered (Aijmer, 2002; Brinton, 1996; Fraser, 1999; Schiffrin, 1987). Moreover, because of having multivariate, multifunctional, and multifaceted nature, they have been investigated from a number of perspectives, revealing their. Since, they are concerned with the implicit side of human communication (Erman, 2001). In this regard Yang (2011) maintains that the studies in the area of DMs fall into two categories: they either focus on a descriptive analysis of the performance of the native speakers of a language or the use of DMs of the target language by non-native speakers. But the analysis of 40 investigations indicates that these studies fall into categories such as the role of DMs, interaction between DMs and other variables, nature and concept of DMs, the use of DMs in a special context, the framework for the analysis of DMs, and the analysis of a specific discourse marker in a specific situation.

Regarding DMs nature and concept, there are three key authors: Aijmer (2002), Fraser (1999), and Schiffrin (1987). Schiffrin (1987, p. 31), as the first researcher raising DMs importance, defines them as "sequentially dependent elements which bracket units of talk". Units of talks, according to her, might be sentences, propositions, speech acts, and tone units, with the function of segmenting sections of an interaction. The term bracket deals with the boundaries of the units and she broadens these boundaries to social life and social organizations. The term sequential dependence indicates that they sequence syntactic units and fit them into a social context.

About a decade later, Fraser (1999, p. 23) has defined them as "a pragmatic class, lexical expressions drawn from the syntactic classes of conjunctions, adverbials, and prepositional phrases". Regarding DMs' function he maintains that they signal a relationship between the segment they introduce and the former segment. According to Aijmer (2002), DMs are greatly context specific and indexed to feelings, attitudes, participants, and nature of texts. They provide clues to the way discourse is segmented and processed, and facilitate the processing and comprehension of the text.

In terms of the role of DMs, the researchers have approached the issue from four perspectives: the social consequences, DMs' function in special situations, DMs as the relationship signaling elements, and classroom interaction. Regarding social consequences, Dafouz-Milne (2008) studied the role of DMs in the construction and attainment of persuasion from a cross-linguistic perspective. She selected two British and Spanish newspapers, "The Times" and "ElPa1's". She wanted to identify meta-discourse markers predominating in these newspapers' discourse and the way they are distributed. She chose 20 opinion columns from each paper. Her findings suggested that both textual and interpersonal meta-discourse markers were present in both newspaper columns, with variations in the distribution and composition of markers and both textual and interpersonal markers were influential in rendering the text persuasive. Concerning social and expressive functions of the particle "xajde" ('come on/let's) in Bulgarian, Tchizmarova (2005) analyzed its hedging functions based on speech act and politeness theory in informal symmetrical discourse. His findings indicated that this particle was an effective politeness marker or a hedge, minimizing the imposition on hearer's autonomy or reducing a potential threat to other speakers' positive face. These functions reflected relationships among speakers, their need to maintain attachments, and focus on emotions.

Applying two pragmatic approaches offered by Blakemore (1987) and Schiffrin (1987) to the analysis of the function of four Modem Greek expressions, Archakis (2001) came to the idea that the two approaches were inadequate to capture the functions of these Greek DMs. Since, Schiffrin's distinctions couldn't reflect the slight variations between the markers examined. Moreover, the contextual effects proposed by Relevance Theory and adopted by Blakemore were not always the parameters connected with DMs directly or indirectly. As a result, he developed an alternative approach elaborating mainly on the basis of Schiffrin's (1987) model.

To study the role DMs as signals of rhetorical relations, Taboada (2006) carried out two different corpus 
studies of conversations and newspaper articles. He analyzed the corpora in terms of rhetorical relations. The results did not reveal a high number of relations signaled. Furthermore, a comparison between the two corpora indicated that genre-specific factors might indicate which relations can be signaled, and which cannot.

To investigate the frequencies and functions of DMs in EFL classroom interaction, Castro (2009) used data from classroom interactions of a non-native teacher of English and five adult students of EFL. Qualitative analysis of his results revealed that discourse markers fulfill a number of textual and interpersonal functions contributing basically to the coherent and pragmatic flow of the discourse generated in classroom interaction.

To prove DMs as functional elements, Matei (2010) placed focus on functionalism and the most relevant theories for a functional analysis of DMs. The researcher's results showed that discourse markers were important functional elements influencing the coherence and cohesion of discourse, played an important part in the interpersonal and expressive use of language, and showed consistency in the institutionalized uses of language in its social and cultural context.

Regarding the interaction between DMs and other variables researchers have approached the issue from five perspectives. To study the interaction between DMs and coherence, Lenk (1998) comparatively analyzed British and American conversations applying the taxonomy offered by Schiffrin (1987).The researcher's findings revealed that DMs were significant for the comprehension of the coherence of conversation and participants were engaged in processing information. Jalilifar (2008) investigated the relationship between university students' writing and DMs through Schiffrin's (1987) framework and concluded that there existed a direct and positive relationship between the quality of the compositions and the frequency of well-functioned DMs. His results also revealed statistically significant differences between the use of DMs and composition quality and high frequency of the use of DMs led to more cohesive texts.

Rahimi and Riasati (2008) investigated the relationship between the explicit vs implicit instruction of DMs and learners' speech. They offered the experimental group five sessions of DMs explicit instruction, 20 minutes every session. They applied semi-structured interview to collect data. Results showed that the control group that received implicit teaching of DMs did not use them frequently. But, the experimental group which received explicit teaching of discourse markers used them frequently in their oral production proving the usefulness of the explicit teaching.

Rahimi (2011) studied the interaction between the use of DMs and writing quality in argumentative and expository compositions of Iranian undergraduate EFL students. He analyzed DMs in argumentative and expository essays by Iranian EFL students. The quantitative analysis of the results indicated that elaborative marker 'and' was the most frequently used DM in both essays and contrastive and inferential markers were the least frequently used ones. On the whole, the mean use of DM was significantly higher in argumentative essays. However, the qualitative analysis of the results revealed that the use of DMs cannot be a significant index of the Iranian EFL students writing quality.

Duran and Unamuno (2001) tried to examine the relationship between specific conversational contexts and the meaning and use of certain DMs. They took into account sociolinguistic variables - such as the situation and the setting of the interaction, the type of participants and the relationship between them. The results revealed that some of the variables in conversational situations restrict the meaning and use of certain DMs in the classroom context. The consequences of the proper use of DMs in educational settings were considered from two perspectives, Yang (2011) maintains that the appropriate use of DMs in classroom can both improve the participation of the students and contribute to learning effectiveness.

Hellermann and Vergun (2007) investigated the use of DMs in the classroom interaction and bilingual interviews of adult learners of English. Their results showed that the subjects used few DMs. They inferred that the active students' better use of discourse markers might be due to the fact that they acquired a good command of US culture. Taglimonte (2005) tried to offer an explanation of the system of the use of DMs in the spoken 
The frequencies and functions of discourse markers in the Iranian university EFL classroom discourse

interactions of the younger Canadian learners. The findings indicated that the use of DMs is not haphazard, random, or indiscriminate, but rather it is systematic. Indeed, DMs do not occur anywhere and their occurrence is quite well thought-out.

Liao (2008) investigated the application of English DMs by male and female Chinese students in a study-abroad context. Amalgamating insights from sociolinguistics and SLA, he used quantitative and qualitative methods to examine the use of DMs, analyze the production of L2 speakers, and investigate the relationship between L2 speakers' complicated social identities, language attitude, and participation in the local community regarding DMs use. The results revealed that the use of both approaches has enabled the researcher to gain a fuller picture of L2 speakers' performance. Moreover, the results showed the restricted range of DM use and some unnatural uses of DMs. Also style seemed to be a more important factor than gender. Quan and Zheng (2012) examined the differences in the use of DMs such as well, I mean, and maybe between native speakers and Chinese English learners. They employed the British National Corpus and Spoken English Corpus of Chinese Learners in their study. Compared with native speakers, Chinese English learners underused well and I mean, but overused maybe.

The last group of studies focused on specific discourse markers in specific situations. This group approached the subject from sequence initiating and historical development outlooks. Bolden (2009) used conversation analysis to examine a large corpus of recorded conversations to explain the role of 'so'. The analysis focused on the use of 'so' for prefacing sequence-initiating actions and demonstrated that speakers used it to indicate the status of the future action. Onodera (2004) investigated the historical process of the development of two different connectives in Japanese: 'demo' and 'na', to emerge as DMs. The results showed that 'demo' appeared to have undergone a positional shift: from a clause-final into an utterance-initial. The functional change in the interjection $n e$ was also associated with the positional shift from the sentence final elements into initial markers.

The majority of these studies focus on a single class, instruction to a single class, and a single particle. Moreover, the studies have a small scale and no attention is given to the teacher's gender. The researchers tried to fill these gaps and provide a better picture of DMs use and function through a comprehensive analysis using both quantitative and qualitative approaches, including four groups of subjects, comparison of teachers'/learners' performance, and the analysis of the role of teachers' gender in the application of DMs in the classroom interaction.

\section{Methodology}

In order to establish a reliable and valid research methodology in the process of investigation, the researchers tried to establish the procedure trustworthiness by gathering credible, dependable, and valid data. To meet this objective, first, constant procedures in data collection /analysis were selected. Then, natural classroom interaction was recorded. Moreover, another instructor was invited to have a say in the interpretation of the instances of DMs functions, the qualitative phase. Finally, the results were compared with others for the sake of verification.

\subsection{The Participants}

The participants in this study consisted of four classes of adult male and female Iranian EFL students, two male, and two female teachers in Arak University, Arak, Iran. There were about twenty students in each class: 15 female and 5 male students in class A, 12 female and 7 male students in class B, 12 female and 9 male students in class $\mathrm{C}$, and 13 female and 8 male students in class D. Their age ranged between 19 and 21 . They came from different parts of Iran. Most of them had Persian as their first language and few had Turkish as their first and Persian as their second language.

They were sophomore BA students majoring in English translation and English literature in Arak University. They attended EFL classes twice a week. The teacher (female) in group A was 27 holding an MA in linguistics 
with five years of experience at university, the instructor (female) in group B was 28 holding an MA in translation studies with six years of experience, the third in group C (male) was 33 possessing an MA in TEFL with 9 years of teaching experience at university and currently a PHD student, and the tutor (male) in group D was 29 holding an MA in translation studies with eight years' experience.

\subsection{Procedures for Data Collection}

The data was collected from four conversation classes in 2013. The discussions were about literature and politics. Participants talked about the Iranian internal and foreign policy and some novels and short stories. Their tasks included reading and speaking. A recorder was used to gather the data. Then, the audio data was transcribed. Subsequently, a spoken text about 30minutes was selected as the main source of information from each class. The texts were the most representative, illustrative, and richest section regarding the interaction between the participants in every class. Then the selected parts of the interactions were transcribed. Random mistakes and errors by participants were not corrected; rather, they were transcribed as they occurred.

\section{Data Analysis}

For displaying the frequency of occurrence and distribution of DMs- the quantitative phase, Fraser's (1999, 2009) taxonomy was applied. In this taxonomy, DMs are classified into four categories: basic, comment and attitude, message relating, and topic relating DMs. Basic DMs are divided into three classes: promise, request, and complaint. Comment and attitude DMs are grouped into five categories: assessment, manner of speaking, evidence, hearsay, and defense markers. Message relating DMs are subdivided into six types: elaborative, inferential, contrastive, interjection, confidence, and focus markers. The fourth classification, topic relating DMs, hint at an aspect of the organization of the ongoing discourse. This category is also subdivided into three groups: discourse management, topic orientation, and attention markers. For the analysis of the pragmatic functions of DMs, Brinton's (1996) classification of DMs functions was employed. Brinton classifies them into two groups: textual and interpersonal functions. The former is divided into eight groups: opening, closing, turn taking/giving markers, fillers/ turn keepers markers, topic switchers, information indicators, sequence/relevance, and repair markers. And the latter is classified into two categories: response/reaction markers or back-channel signals and confirmation-seekers or face savers.

The data was analyzed quantitatively and qualitatively. The quantitative aspect of the investigation was executed by the application of descriptive statistics involving simple statistical analyses such as lexical size and frequency to show the occurrences and distribution of DMs in teachers' and students' classroom discourse. Applying Fraser's $(1999,2009) 94$ item inventory of DMs, the researchers carried out the quantitative analyses. The qualitative side of the analysis dealt with the recognition, identification, classification, and description of the pragmatic functions of the DMs employed by the teachers and students through applying Brinton's (1996) framework.

\section{Results and Discussion}

Concerning the first research question, the interaction between the lexical size and the application of DMs, the researchers first analyzed the general lexical size and the proportion of DMs frequency in the four classes. As shown in Table 1, the total lexical size in the four samples is 13658 words. Of which $26.6 \%$ belongs to group A, $24.8 \%$ to group B, $24 \%$ to group C, and $24.4 \%$ to group D. And the total DMs occurred is 1058 cases, of which $24 \%$ goes to group A, $25 \%$ to group B, $23.75 \%$ to group C, and $27.1 \%$ to group D. Table 1 reveals that the lexical sizes of the four groups are somehow similar except for groups A and B and the occurrences of DMs in these groups do not vary greatly. Moreover, DMs occur 1058 times in the samples accounting for $7.76 \%$ of the entire corpus distribution in the creation of discourse. Compared with 19\% distribution in Castro (2009), this proportion seems to be low, requiring further analysis, consideration, and reorientation in EFL education.

This relatively small range of DMs use is in line with Djigunovic and Vickov (2010) research in Croatian 
EFL situation, Ying (2007) in Japanese and Chinese EFL context, and Asik and Cephe (2013) in Turkey. It might be due to the typical neglect of knowledge of DMs as an educational reality resulting in inadequate input for English DMs in Iranian university EFL context which is in line with Trillo (2002) study in Spain. Taking educational issues into account and comparing German EFL learners with the native speakers, Weinert (1998) holds that nonnative speakers' much smaller range of DMs use can be due to learning materials influence, problems in classroom learning, and the way they are taught in EFL context.

Culture is another variable. Culture is also taken as a determining factor. Hellermann and Vergun (2007) come to the idea that using few DMs is the result of being isolated from target language culture. Because, among their subjects there were some focal students used more DMs and had the experience of living in America and were more acculturated to the US.

\section{Table 1}

Occurrences and frequencies of lexical size and discourse markers by the teacher sand the students

\begin{tabular}{llllll}
\hline & Class A & Class B & Class C & Class D & Total \\
\hline Lexical Size & 3638 & 3400 & 3287 & 3333 & 13658 \\
Lexical frequency & $26.6 \%$ & $24.8 \%$ & $24 \%$ & $24.4 \%$ & $100 \%$ \\
DMs Size & 255 & 263 & 252 & 288 & 1058 \\
DMs frequency & $24 \%$ & $25 \%$ & $23.75 \%$ & $27.1 \%$ & $100 \%$ \\
\hline
\end{tabular}

To answer the second question, directing the category and the frequency of DMs in the four samples, the distribution of all DMs were analyzed for each class. Tables 2, 3, 4, and 5, display the category, frequency, and distribution of six groups of DMs in the classes. Table 2 reveals the results for group A.As shown in Table 2, the highest degree of distribution belongs to elaborative markers with 180 occurrences accounting for $70 \%$ of the data with 'and' as the most frequent marker, inferential markers with 52 occurrences stay in the second rank making up for $20.3 \%$ of the distribution, contrastive markers with 25 occurrences take the third rank explaining $9.8 \%$ of the cases, and attention markers with 8 frequencies are placed in the fourth position. The lowest degree of distribution relates to focus markers with 3 instances justifying $1 \%$ of the data and confidence and request markers are in the third and fourth rank possessing the lowest distributions.

\section{Table 2}

The distribution of Discourse Markers in group A by the teacher sand the students

\begin{tabular}{cllllll}
\hline Category & Distribution & Distribution & Distribution & Distribution & Distribution & Total \\
\hline Contrastive & However & Instead & But & & & Fre.9.8\% \\
& $2.3 \%$ & $1 \%$ & $6.66 \%$ & & Occ. 25 \\
Elaborative & Also & And & Well & That is & Or & Fre. $70 \%$ \\
& $12 \%$ & $31.3 \%$ & $17.25 \%$ & $4.7 \%$ & $4.7 \%$ & Occ. 180 \\
Inferential & Then & So & Since & If & Fre. $20.3 \%$ \\
& $5 \%$ & $3 \%$ & $6.2 \%$ & $2.7 \%$ & Occ. 52 \\
Confidence & Indeed & Definitely & & & Fre. $1.9 \%$ \\
& $0.39 \%$ & $1.5 \%$ & & & Occ. 5 \\
Focus & Only & & & & Fre. $1 \%$ \\
& $1 \%$ & & & & Occ. 3 \\
Attention & Now & Look & & & Fre. $3 \%$ \\
& $1.5 \%$ & $1.5 \%$ & & & Occ. 8 \\
\hline
\end{tabular}

Table 3 represents the distribution of DMs in group B with 263 occurrences explaining $7.8 \%$ of distribution in the sample. In this class we also come across with a similar distribution to the former class, i.e. elaborative markers occurred 126 times and explained $47.3 \%$ of the distribution in which 'well' is the most frequent marker. Inferential markers came about 31 times and justified 11.65\% revealing 'so' as the most frequent marker. Also, contrastive markers took place in 28 instances accounting for $10.5 \%$ of cases with 'but' as the highly frequent marker. Confidence markers occupy the fourth place occurring 15 times with $5.63 \%$ of distribution. Attention markers happened 21 times with $7.8 \%$ distribution. The least distribution is correlated with focus and attention 
Nejadansari, D. \& Mohammadi, A. M.

markers occurring 11 times and substantiating only $4 \%$ of distribution for each.

Table 3

The distribution of Discourse Markers in group B by the teacher sand the students

\begin{tabular}{cllllll}
\hline Category & Distribution & Distribution & Distribution & Distribution & Distribution & Total \\
\hline Contrastive & However & Instead & But & & & Fre. 10.5 \\
& $0.3 \%$ & $2.7 \%$ & $12.5 \%$ & & Occ. 28 \\
Elaborative & Also & And & Well & That is & Or & Fre. $47.3 \%$ \\
& $8.6 \%$ & $6.27 \%$ & $23.9 \%$ & $7.8 \%$ & $1 \%$ & Occ. 126 \\
Inferential & Then & So & Since & & Fre. $11.65 \%$ \\
& $1.8 \%$ & $6 \%$ & $3.7 \%$ & & Occ. 31 \\
Confidence & & Definitely & & & Fre.5.63\% \\
& & $5.63 \%$ & & & Occ. 15 \\
Focus & Only & Just & $1 \%$ & & $0.3 \%$ & Fre. $4 \%$ \\
& $2.63 \%$ & Loourse & & Occ. 11 \\
Attention & Now & Low & & & & Fre. $4 \%$ \\
& $6 \%$ & $1.8 \%$ & & & Occ. 11 \\
\hline
\end{tabular}

The occurrences and the distributions of DMs in group $\mathrm{C}$ are displayed in Table 4 with 252instances and $7.66 \%$ of the distribution regarding the whole lexical size in the teacher and the students' classroom interaction. In this class, too, message relating DMs enjoy the highest rank: elaborative markers with 148 instances and $58.7 \%$ of distribution in which 'and' is overused, contrastive markers with 40 examples and $15.8 \%$ of distribution, and inferential markers with 29 cases and $11.5 \%$ of distribution. Basic DMs such as request with 8 items and $3 \%$ of distribution and topic relating DMs such as attention markers with 19 instances and $7.5 \%$ distribution hold the fourth and the fifth position. Focus markers, with 5 cases and $1.9 \%$ distribution, are in the sixth rank. The lowest place is kept by confidence markers with 2 instances and $0.7 \%$ distribution.

Table 4

The distribution of Discourse Markers in group C by the teacher sand the students

\begin{tabular}{|c|c|c|c|c|c|c|}
\hline Category & Distribution & Distribution & Distribution & Distribution & Distribution & Total \\
\hline \multirow[t]{2}{*}{ Contrastive } & However & Instead & But & & & Fre.15.8\% \\
\hline & $2.26 \%$ & $0.7 \%$ & $11.25 \%$ & & & Occ. 40 \\
\hline \multirow[t]{2}{*}{ Elaborative } & Also & And & Well & That is & Or & Fre. $58.7 \%$ \\
\hline & $6.95 \%$ & $26.5 \%$ & $11.69 \%$ & $7.41 \%$ & $5 \%$ & Occ. 148 \\
\hline \multirow[t]{2}{*}{ Inferential } & Then & So & Since & If & & Fre. $11.5 \%$ \\
\hline & $1.56 \%$ & $1.95 \%$ & $5.46 \%$ & $2.26 \%$ & & Occ. 29 \\
\hline \multirow[t]{2}{*}{ Confidence } & Indeed & Definitely & & & & Fre. $0.7 \%$ \\
\hline & 0 & $1.43 \%$ & & & & Occ. 2 \\
\hline \multirow[t]{2}{*}{ Focus } & Only & & & & Of course & Fre. $1.9 \%$ \\
\hline & $0.7 \%$ & & & & $0.14 \%$ & Occ. 5 \\
\hline \multirow[t]{2}{*}{ Attention } & Now & Look & & & & Fre. $7.5 \%$ \\
\hline & $4.66 \%$ & $2.66 \%$ & & & & Occ. 19 \\
\hline \multirow[t]{2}{*}{ Request } & Please & & & & & Fre. $3 \%$ \\
\hline & $7.8 \%$ & & & & & Occ. 8 \\
\hline
\end{tabular}

Group D has got the highest occurrences and distribution of DMs with 288 instances and $8.64 \%$ of distribution regarding the lexical size in the class. In this group the first two categories are occupied by message relating DMs, elaborative markers with 183 instances and $63.5 \%$ distribution overusing 'well' and inferential markers with 33 examples and $11.4 \%$ distribution with 'then' as the most frequent marker. Evidence markers as an instance of comment DMs include 26 cases and $9 \%$ distribution with 'in fact' as the most frequent marker, are in the third place. Contrastive markers with 19 cases of occurrence and $6.5 \%$ of distribution are in the fourth grade overusing 'but'. Comprising 17 examples and 5.9\% distribution, attention markers as an instance of topic relating DMs form the fifth category. With 6 instances and 2\% of distribution, focus markers appear in the sixth grade. The lowest rank is owned by confidence markers with only 2 cases and $0.6 \%$ distribution as shown in Table 5. 
The frequencies and functions of discourse markers in the Iranian university EFL classroom discourse

Table 5

Frequencies and occurrences of DMs in group D by the teacher sand the students

\begin{tabular}{lllllll}
\hline \multicolumn{1}{c}{ Category } & Distribution & Distribution & Distribution & Distribution & Distribution & Total \\
\hline Contrastive & However & Instead & But & & & Fre.7.86\% \\
DMs & $1.96 \%$ & $0.32 \%$ & $5.1 \%$ & & Occ. 24 \\
Elaborative & Also & And & Well & That is & Or & Fre.60.5\% \\
& $7.47 \%$ & $12 \%$ & $18.5 \%$ & $16.88 \%$ & $3.92 \%$ & Occ. 183 \\
Inferential & Then & So & Since & If & & Fre. $12.4 \%$ \\
& $4.56 \%$ & $2.28 \%$ & $3.53 \%$ & $3.27 \%$ & & Occ. 38 \\
Confidence & Indeed & Definitely & & & & Fre. $1.7 \%$ \\
& $0.32 \%$ & $0.32 \%$ & & & Occ. 5 \\
Focus & Only & & & $1.6 \%$ & Fre. $1.96 \%$ \\
& $0.32 \%$ & & & & Occ. 6 \\
Attention & Now & Look & & & & Fre.6.2\% \\
& $5.4 \%$ & $0.64 \%$ & & & Occ. 19 \\
Evidence & In fact & & & & Fre. $8.52 \%$ \\
& $8.51 \%$ & & & & Occ. 26 \\
\hline
\end{tabular}

As the Tables 2-5 reveal message relating markers such as contrastive, elaborative, and inferential markers have gained the highest frequency counts in all four groups. In groups B, C, and D the classroom discussion was about the short stories and in group A it was about the Iranian politics requiring the elaboration of ideas, revealing contrast, and expression of inference. Their dominance and high frequency might be due to the fact that they are learned easily by EFL students, needed first in language learning, and are used more frequently than the others because of their uncomplicated semantic characteristics. Such a dominance and justification is reported by Jalilifar (2008) in Iranian EFL students' writing, by Martinez (2004) in Spain, and by Quan and Zheng (2012) in China. Moreover, as Fraser (1999) maintains these DMs provide a series of potentials for showing relationships between text sections making them easily applicable. Then there happened confidence, focus, attention, and request markers with somehow low degrees of occurrence. Furthermore, no comment, attitude, discourse management, and topic orientation markers are applied in these groups. Such an inadequate application is reported by Martinez (2004) in Spain and Mirshamsi and Allami (2013). The limited application of these categories reveals a week point calling for more attention in Iranian EFL context. The argument is that the Iranian EFL curriculum offers two courses in grammar without any attention to pragmatic aspects of these linguistic devices and as a result no explicit instruction is offered in Persian educational contexts. Also from semantic point of view these items are empty (Matei, 2010). Therefore, it is critical for teachers and curriculum designers to help learners appreciate the view of pragmatic meaning, i.e. what people intend instead of what words mean (Chanet, 2009).

The data displayed in Table 6 represents the ratio of DMs applied by the teachers and the students in the samples revealing the answer for the third question directing the relationship between teachers' and students' performance on DMs. In group A, 60.3\% of DMs are applied by the students and $39.6 \%$ by the teacher. But in group B the teacheremployed61.9\% of DMs and student used 37.9\%. In group C, 59.1\% of DMs are applied by the teacher and $40.8 \%$ by the students. In group D the teacher implemented $63.8 \%$ and the students $36.1 \%$ of DM. The distribution in group A reveals a student-centered approach to classroom discourse. Students applied more than $60 \%$ of DMs in her class. It is the opposite in group B, revealing the teacher's dominance. 162 DMs are utilized by her which is less than two thirds of the cases and 101 instances are applied by the students revealing more than one thirds. The results in groups $\mathrm{C}$ and $\mathrm{D}$ reveal the teachers' superiority in the employment of DMs over students and it can be due to the influence of their social class, language proficiency, or more experience in learning and teaching EFL as pointed to by Vergun (2005) in the study of nonnative teachers classroom discourse. 
Nejadansari, D. \& Mohammadi, A. M.

Table 6

The ratio of the distribution and occurrences of DMs utilized by the teachers and the students

\begin{tabular}{llll}
\hline & Total DMs & Teacher & Students \\
\hline Class A & 255 & $\begin{array}{l}\text { Distribution:39.6\% } \\
\text { Occurrence: 101 }\end{array}$ & $\begin{array}{l}\text { Distribution:60.3\% } \\
\text { Occurrence: 154 }\end{array}$ \\
\hline Class B & 263 & $\begin{array}{l}\text { Distribution:61\% } \\
\text { Occurrence: } 162\end{array}$ & $\begin{array}{l}\text { Distribution:37.9\% } \\
\text { Occurrence: } 101\end{array}$ \\
\hline Class C & 252 & $\begin{array}{l}\text { Distribution:59.1\% } \\
\text { Occurrence: 149 }\end{array}$ & $\begin{array}{l}\text { Distribution:40.8\% } \\
\text { Occurrence: 103 }\end{array}$ \\
\hline Class D & 288 & Distribution:63.8\% & Distribution: 36.1\% \\
& & Occurrence: 184 & Occurrence: 104 \\
\hline
\end{tabular}

Moreover, Table 6 represents the proportion of DMs applied by the teachers in each group providing the answer for the interaction between the teachers' gender and the application of DMs (the fourth question). The groups $\mathrm{A}$ and $\mathrm{B}$ were run by female teachers and the instructors in the groups $\mathrm{C}$ and $\mathrm{D}$ were male. The female instructor in group A used 39.6\% of DMs and in group B $61 \%$ of DMs. The male instructor in group C utilized $59.1 \%$ of DMs and in group D employed $63.8 \%$ of the whole DMs. Male instructors in groups C and D made use of $31.4 \%$ of DMs and female teachers in groups A and B applied $24.8 \%$ of DMs. In order to confirm the significance quantitatively and show the interaction between gender and the application of DMs in the creation of discourse, student t-test was run on the data and revealed that the difference between male and female teachers in the formulation of discourse coherence was not significant.

Table 7 represents the distribution of DMs put into practice by the four Iranian EFL teachers in Arak University, supplying the answer for the fifth question. Basing the analysis on the 94 item inventory adapted from Fraser (1999, 2009), it appeared that the teachers applied basic, message relating, and topic relating DMs. Elaborative markers have got the highest degree of distribution $(29.5 \%)$ in which 'well' has got the highest distribution in Iranian EFL teachers' classroom discourse. Inferential markers get the second rank in the studied teachers' classroom interaction (7\%) with 'since' as the most frequent DM. The third place belongs to contrastive markers with 5.4\% distribution with 'but' as the highly frequent DM. Attention markers are placed in the fourth rank with $3.4 \%$ frequency in which 'now' is the most frequent one. The fifth position is taken by request markers with $3 \%$ frequency of occurrence. The next category is achieved by focus markers with $1.8 \%$ distribution. And the least degree of occurrence is realized by confidence markers with $1.6 \%$ occurrence. However, there are a number of points to be considered. First the teachers in question did not utilize any assessment, manner of speaking, hearsay, defense, discourse management, and topic orientation markers. Next, there is no harmony in those DMs applied by the instructors.

\section{Table 7}

The ratio of the distribution and occurrences of DMs utilized by the teachers

\begin{tabular}{lllllll}
\hline Type of DM & Distribution & Distribution & Distribution & Distribution & Distribution & Total \\
\hline Contrastive & However & Instead & But & & & Fre. $5.4 \%$ \\
Markers & $0.6 \%$ & $0.9 \%$ & $3.8 \%$ & & Occ. 58 \\
Elaborative & Also & And & Well & That is & Or & Fre. $29.5 \%$ \\
Markers & $4.7 \%$ & $5.4 \%$ & $12 \%$ & $5.2 \%$ & $2 \%$ & Occ314 \\
Inferential & Then & So & Since & On the con. & & Fre. $7 \%$ \\
Markers & $1.7 \%$ & $2 \%$ & $2.5 \%$ & $0.9 \%$ & & Occ. 76 \\
Confidence & Indeed & Definitely & & & & Fre. $1.6 \%$ \\
Markers & $0.1 \%$ & $1.5 \%$ & & & Of course & Fre. $1.8 \%$ \\
Focus & Only & & & & Occ: 20 \\
Markers & $0.9 \%$ & & & & Fre. $3.4 \%$ \\
Attention & Now & Look & & & & Occ: 37 \\
Markers & $2.6 \%$ & $0.8 \%$ & & & & Fre. $3 \%$ \\
Request & Please & & & & & Occ. 4 \\
Markers & $3 \%$ & & & & & \\
\hline
\end{tabular}


Table 8 displays the frequencies for DMs applied by the EFL students in Arak University, offering the answer for the sixth question directing the type and frequency of DMs in the Iranian university EFL students' interactions. As Table 8 reveals of the four categories of Fraser's taxonomy, three categories of request, message relating, and topic relating DMs are put into practice in the students' discourse. The most frequently applied DMs are elaborative markers with $28.5 \%$ of distribution accompanied by 'and' (12.4\%) as the most frequently applied DM 'also' (4.2\%), 'well' (6\%), 'that is' (4.5\%), and 'or' (1.5\%).Next category with $6.6 \%$ frequency include the inferential markers along with four varieties of 'then' (1\%), 'so' $(1 \%)$, 'since' $(2.9 \%)$, and 'on the condition' (2\%).With $5.8 \%$ of distribution, contrastive markers came third alongside' however' $(0.7 \%)$, 'instead' $(0.2 \%)$, and 'but' (4.8\%).This highly frequent application of message relating DMs is reported in Aşık and Cephe's (2013) study on Turkish learners, Martinez (2004) on Spanish EFL learners, and Quan and Zheng (2012) on Chinese students.

The fourth rank is taken up by attention markers with $2.7 \%$ of distribution employing DMs such as 'now' $(1.9 \%)$ and 'look' $(0.75 \%)$. Request, confidence, and focus markers occur at the lower ranks in the categories explored. Following their teachers' behavior, the students also did not employ any assessment, manner of speaking, evidence, hearsay, defense, discourse management, and topic orientation markers. The inadequate use of these categories justifies the need for reformulation of English syllabus or curriculum and is related to studies done by Martinez (2004) in Spain, Quan and Zheng (2012) in China, and Onodera (2004) in Japan.

\section{Table 8}

The frequencies of DMs employed by EFL students

\begin{tabular}{lllllll}
\hline \multicolumn{1}{c}{ Type of DM } & Distribution & Distribution & Distribution & Distribution & Distribution & \multicolumn{1}{c}{ Total } \\
\hline Contrastive & However & Instead & But & & & Fre. $5.8 \%$ \\
Markers & $0.7 \%$ & $0.2 \%$ & $4.8 \%$ & & & Occ. 62 \\
Elaborative & Also & And & Well & That is & Or & Fre. $28.5 \%$ \\
Markers & $4.2 \%$ & $12.4 \%$ & $6 \%$ & $4.5 \%$ & $1.5 \%$ & Occ305 \\
Inferential & Then & So & Since & On the con. & & Fre. $6.6 \%$ \\
Markers & $1 \%$ & $1 \%$ & $2.2 \%$ & $2 \%$ & & Occ. 71 \\
Confidence & Indeed & Definitely & & & & Fre. $0.6 \%$ \\
Markers & $0.9 \%$ & $0.5 \%$ & & & Of course & Occ: 7 \\
Focus & Only & & & $0.1 \%$ & Fre. $0.47 \%$ \\
Markers & $0.28 \%$ & & & & Frc: 5 \\
Attention & Now & Look & & & & Occ: 29 \\
Markers & $1.97 \%$ & $0.75 \%$ & & & & Fre. $0.56 \%$ \\
Request & Please & & & & Occ. 6 \\
Markers & $0.7 \%$ & & & & \\
\hline
\end{tabular}

Because of the fact that DMs are semantically empty and as a result no longer reliable, they should only be investigated and analyzed from a functional point of view. This lack of semantic meaning is made up for by the existence of pragmatic meaning, as a constant-changing meaning in full harmony with the dynamics of language use involving their complicated and multi-dimentional functions. DMs functions can only be identified according to the communicative objective in the situation- what people intend rather than what words mean. And the wide range of the functional categories of DMs is the result of reference to various communicative domains such as information joining, discourse structuring, the system of turn-exchange, etc. Then depending on a specific domain area, DMs gain their specific functional category (Silva, 2006).

Consequently, such a study can suffer from the problem of the domains boundary, that is, these domains are indistinct, without crystal clear borders, and the predominant function is provided in the specific context (Erman, 2001; Matei, 2010).According to Erman (2001) monitoring discourse is the major and fundamental function of DMs.

In order to analyze the predominant functions of DMs in these EFL teachers' and students' interactions (the seventh question), the model offered by Brinton (1996) was applied. According to her inventory of functional 
Nejadansari, D. \& Mohammadi, A. M.

analysis, DMs are classified into two classes: textual and interpersonal. This inventory is subdivided into ten categories. Textual functions refer to the speaker's system of meaning construction to produce a text, thereby creating cohesive patterns of discourse. Interpersonal functions deal with the addressor and addressee role, that is, the social exchange. The subdivisions of textual functions include opening markers, closing markers, turn taking/giving, fillers/ turn keepers, topic switchers, information indicators, sequence/relevance markers, and repair markers. Interpersonal functions are subdivided into response/reaction markers, back-channel signals, confirmation-seekers, and face-savers.

Tables 9-12 provide categorization and exemplification of functions of DMs in the four groups under investigation. Identification, description, and exploration of these functions are based on the analysis of each DM in its local context used by the teachers and the learners. These instances illustrate the qualitative analysis performed on the data.

Table 9

Actual instances of DMs functions in class A produced by the teacher $(T)$ and the students $(S)$

\begin{tabular}{|c|c|c|}
\hline & Categories & Instances \\
\hline 1 & $\begin{array}{l}\text { Opening } \\
\text { marker }\end{array}$ & $\begin{array}{l}\text { T: Look, I said Egypt has received part of the loan from Arab countries. } \\
\text { S: Well, Iranian government has taken lots of political steps to start relations with Egypt. }\end{array}$ \\
\hline 2 & Closing marker & $\begin{array}{l}\text { T: } \ldots \underline{\text { So, }} \text { you have to have a dictionary in the class. } \\
\text { S: .... In fact, the writer thinks that the international issues are vitally important and critical. }\end{array}$ \\
\hline 3 & Turn takers & $\begin{array}{l}\text { T: Well, where was the meeting held? They did meet each other in a special place. } \\
\text { S: Then, we can say it means weak unity. }\end{array}$ \\
\hline 4 & Turn givers & $\begin{array}{l}\text { T: Well, will you say your view of the consequences of establishing the political ties? } \\
\text { S: I don't see our isolation of our country, since was an economic discussion, wasn't it? }\end{array}$ \\
\hline 5 & $\begin{array}{l}\text { Fillers/Turn } \\
\text { keepers }\end{array}$ & $\begin{array}{l}\text { T: .... Well, I think it will result in the isolation of the nation from the world. } \\
\text { S: ...... Since, it shows the importance of economic cases. }\end{array}$ \\
\hline 6 & Topic switchers & $\begin{array}{l}\text { T: However, Iranian parties, politicians, and leaders try to develop their international trade. } \\
\text { S:.....Instead, Iranian and Western authorities have turned their attention to economic affairs.. }\end{array}$ \\
\hline 7 & $\begin{array}{l}\text { Information } \\
\text { indicators }\end{array}$ & $\begin{array}{l}\text { T: Also, the diplomat said Velayati is going to nominate for Iranian presidential champagne. } \\
\text { S: What they imply is not favorable, that is, they are opposing the negotiation process. }\end{array}$ \\
\hline 8 & $\begin{array}{l}\text { Sequence } \\
\text { /relevance } \\
\text { markers }\end{array}$ & $\begin{array}{l}\text { T: Then definitely this loan is received easily without following the needed our actions. } \\
\text { S: The text says if they expand political ties with Iran, they can receive the loans and it doesn't } \\
\text { result in ending the relation with the West. }\end{array}$ \\
\hline 9 & Repair markers & $\begin{array}{l}\text { T: Well, what he said is not implied in the text. } \\
\text { S: } \text { However, it is not the case, both parties denied the case. }\end{array}$ \\
\hline 10 & $\begin{array}{l}\text { Response/reacti } \\
\text { on markers }\end{array}$ & $\begin{array}{l}\text { T: } \text { So, what did he say a few seconds ago? } \\
\text { S: } \underline{\text { But, Iranian authorities have implied their willingness to find a political solution. }}\end{array}$ \\
\hline 11 & $\begin{array}{l}\text { Confirmation } \\
\text { seekers/ } \\
\text { face-savers }\end{array}$ & $\begin{array}{l}\text { T: No instance found. } \\
\text { S: } \underline{\text { But, it reveals Iranian desire to decrease the tensions and stop the sanctions. }}\end{array}$ \\
\hline
\end{tabular}

Table 10

Sample instances of DMs functions in class B applied by the teacher $(T)$ and the students $(S)$

\begin{tabular}{|c|c|c|}
\hline & Categories & Instances \\
\hline 1 & Opening marker & $\begin{array}{l}\text { T: Well, it is not clear in this part of the story, you should see the next section. } \\
\text { S: } \quad \text {......Well, the character says: "I am going, where? I don't know". }\end{array}$ \\
\hline 2 & Closing marker & $\begin{array}{l}\text { T:... So, what is your suggestion? } \\
\text { S: ... and I don't know what it means. }\end{array}$ \\
\hline 3 & Turn takers & $\begin{array}{l}\text { T:...But I think imagination is not that much influential. } \\
\text { S: Of course, no it is something personal }\end{array}$ \\
\hline 4 & Turn givers & $\begin{array}{l}\text { T: ..... Well, can we say it means myth? } \\
\text { S: No instance found. }\end{array}$ \\
\hline 5 & $\begin{array}{l}\text { Fillers/Turn } \\
\text { keepers }\end{array}$ & $\begin{array}{l}\text { T: ...... Well, so what he said can be true, since those words are synonym. } \\
\text { S: Now, the meaning might be lover or friend. }\end{array}$ \\
\hline 6 & Topic switchers & $\begin{array}{l}\text { T: ....Thus you can think of another scenario and see how the function of the character change. } \\
\text { S: ..... Or from the very beginning we can think of a more comprehensive explanation. }\end{array}$ \\
\hline 7 & $\begin{array}{l}\text { Information } \\
\text { indicators }\end{array}$ & $\begin{array}{l}\text { T: That is, words can help us get the message, judge, and express our point of view. } \\
\text { S: Well, they use imagination to show the concept unimportant and we use it for negative cases }\end{array}$ \\
\hline
\end{tabular}


The frequencies and functions of discourse markers in the Iranian university EFL classroom discourse

\begin{tabular}{|c|c|c|}
\hline 8 & $\begin{array}{l}\text { Sequence } \\
\text { /relevance markers }\end{array}$ & $\begin{array}{l}\text { T: So we can put it this way and get the message across clearly. } \\
\text { S: It is common and so crystal clear in English. }\end{array}$ \\
\hline 9 & Repair markers & $\begin{array}{l}\text { T: We are interpreting the story; however, we should describe it. } \\
\text { S: No, dream is not true; definitely, it means imagination. }\end{array}$ \\
\hline 10 & $\begin{array}{l}\text { Response/reaction } \\
\text { markers }\end{array}$ & $\begin{array}{l}\mathrm{T}: \text { Look, we never say something is the best or worst. } \\
\text { S: ... But, myth is definitely unreal. }\end{array}$ \\
\hline 11 & $\begin{array}{l}\text { Confirmation } \\
\text { seekers/ } \\
\text { face-savers }\end{array}$ & $\begin{array}{l}\text { T: ... Yes in fact they seem civilized or for instance polite. } \\
\text { S: } \underline{\text { So, }} \text { what is reminded in the character's mind is something that makes him hopeless. }\end{array}$ \\
\hline
\end{tabular}

Table 11

Sample instances of DMs functions in class C applied by the teacher $(T)$ and the students $(S)$

\begin{tabular}{|c|c|c|}
\hline & Categories & Instances \\
\hline 1 & Opening marker & $\begin{array}{l}\text { T: Of course, we can think of your understanding, but it is somehow odd in that situation. } \\
\text { S: ...So, it is not implied in the story and there is a similarity between them. }\end{array}$ \\
\hline 2 & Closing marker & $\begin{array}{l}\text { T:... So, it moved upward and made a loud noise. } \\
\text { S: No instance is found. }\end{array}$ \\
\hline 3 & Turn takers & $\begin{array}{l}\text { T:... Of course, it depends on your perspective, how you see the setting in the story. } \\
\text { S: But, here there is a strange state. I thought that has taken off part of his shirt. }\end{array}$ \\
\hline 4 & Turn givers & $\begin{array}{l}\text { T: ..... Now, will you say what happened to the bird in the story? Well, who is next? } \\
\text { S: She is right. Then, what does it mean by witch here? }\end{array}$ \\
\hline 5 & Fillers/Turn keepers & $\begin{array}{l}\text { T: ...... Well, let's put the subject at the very beginning and see how the meaning changes. } \\
\text { S:Yeah, so what does the word 'another' refer to here? }\end{array}$ \\
\hline 6 & Topic switchers & $\begin{array}{l}\text { T:It depends on how you see the scenario or we can say he has put his shirt on his shoulder. } \\
\text { S:Is the color of the bird in the story yellow and red or it is because of its fast upward move. }\end{array}$ \\
\hline 7 & $\begin{array}{l}\text { Information } \\
\text { indicators }\end{array}$ & $\begin{array}{l}\text { T:What you said isn't true in literature; that is, your style should be changed. } \\
\text { S: It is clear which cases are similar and which events are different. }\end{array}$ \\
\hline 8 & $\begin{array}{l}\text { Sequence /relevance } \\
\text { markers }\end{array}$ & $\begin{array}{l}\text { T: ...... Then he takes off the shirt and took his way down the road. } \\
\text { S: As I remember they crossed the rocks and moved towards the lake. }\end{array}$ \\
\hline 9 & Repair markers & $\begin{array}{l}\text { T: However, from stylistic point of view what you said is not true } \\
\text { S: But, here, look it is a bit strange. I imagined he has taken off half of his shirt. }\end{array}$ \\
\hline 10 & $\begin{array}{l}\text { Response/reaction } \\
\text { markers }\end{array}$ & $\begin{array}{l}\mathrm{T}: \text { But, well, the discussion is not about nonliterary text } \\
\mathrm{S}: \underline{\text { That is, the way we should say it is formal? }}\end{array}$ \\
\hline 11 & $\begin{array}{l}\text { Confirmation } \\
\text { seekers/ face-savers }\end{array}$ & $\begin{array}{l}\text { T: ... Yes, now my interpretation of the case is that he is hardhearted, isn't he? } \\
\text { S: I know, but , think about it what I said is true, isn't it? }\end{array}$ \\
\hline
\end{tabular}

Table 13 demonstrates the general system of DMs functions applied in all four classes by the Iranian EFL teachers and the students. According to Table 13 interpersonal functions have got the highest frequency. Applying DMs to indicate information has got the highest frequency in groups A, C, and D: 46.6\% in group A, 28.5 in group C, and $26 \%$ in group D. But in group B, fillers were the most frequent ones (18.7\%). They included DMs such as well, of course, in fact, but, only, I mean, since, and, definitely, that is, and also. The second highly applied functions are fillers in group $\mathrm{A}$, information indicators in group B, and sequence markers in groups $\mathrm{C}$ and D. The third rank goes with opening markers in group A, confirmation seekers in group B, and fillers in groups $\mathrm{C}$ and $\mathrm{D}$. In the fourth position stay sequence markers in group $\mathrm{A}$, topic switchers in group B, opening markers in groups $\mathrm{C}$ and D. Topic switchers are placed in fifth rank in group A, sequence markers in group B, repair markers in group $\mathrm{C}$, and turn taking markers in group $\mathrm{D}$. The least applied functions belong to turn taking markers in group A, and closing markers in groups B, C, and D. As Table 13 reveals generally the lowest frequencies belong to closing markers, $1 \%$ and the highest frequencies to information indicators, revealing disharmony. This overuse and underuse might be due to different sources such as instructors, textbooks, and the context of classroom interaction. The case of textbooks is suggested by Muller (2004) study on German learners of English and Rahimi (2011). The students' relationship in the classroom may not facilitate and provide the proper and the most likely context for various interpersonal usages. This result and justification is in line with Hellermann and Vergun's (2007) investigation on Spanish learners. 
Nejadansari, D. \& Mohammadi, A. M.

Table 12

Sample instances of DMs functions in class D applied by the teacher $(T)$ and the students $(S)$

\begin{tabular}{|c|c|c|}
\hline & Categories & Instances \\
\hline 1 & Opening marker & $\begin{array}{l}\text { T: Now I think the story is clear very well because of . ......... } \\
\text { S: } \ldots \ldots \text { So, they wanted to shake hands and ....... }\end{array}$ \\
\hline 2 & Closing marker & $\mathrm{T}: \ldots$ Well, there is nothing to be discussed now. \\
\hline 3 & Turn takers & $\begin{array}{l}\text { T:... On the condition that you change its place in the sentence. ... } \\
\text { S: That is, their character is introduced in the story clearly. }\end{array}$ \\
\hline 4 & Turn givers & T: ..... Well, who is going to tell us something about the story? Now, what is the suggestion? \\
\hline 5 & $\begin{array}{l}\text { Fillers/Turn } \\
\text { keepers }\end{array}$ & $\begin{array}{l}\text { T: ...... In fact, they used bookish language which is not proper for real life situations. } \\
\text { S: They wanted to do something, now, what was it? Not sure. }\end{array}$ \\
\hline 6 & Topic switchers & $\begin{array}{l}\text { T:It means confident, well it also means explicit } \\
\text { S:As I see they are ashamed of their behavior or they are doubtful. }\end{array}$ \\
\hline 7 & $\begin{array}{l}\text { Information } \\
\text { indicators }\end{array}$ & $\begin{array}{l}\mathrm{T}: \text { That is, it needed time to be processed in your mind. } \\
\mathrm{S}: \text { The sun was setting, but still it was shining. }\end{array}$ \\
\hline 8 & $\begin{array}{l}\text { Sequence } \\
\text { /relevance } \\
\text { markers }\end{array}$ & $\begin{array}{l}\text { T: They wanted to shake hands first and introduce themselves. } \\
\text { S: ..........Then, we can find a suitable name for it, can't we? }\end{array}$ \\
\hline 9 & Repair markers & $\begin{array}{l}\mathrm{T} \text { : But the point is the children were lying on the ground and could not be seen. } \\
\mathrm{S} \text { : } \text { Of course, we could separate their characters roles and describe them clearly. }\end{array}$ \\
\hline 10 & $\begin{array}{l}\text { Response/reaction } \\
\text { markers }\end{array}$ & $\begin{array}{l}\text { T: I wanted to search the net, sine I could not find it from the books. } \\
\text { S: ... Anyway, the appearance from the very first contact reveals that is polite or not. }\end{array}$ \\
\hline 11 & $\begin{array}{l}\text { Confirmation } \\
\text { seekers/ } \\
\text { face-savers }\end{array}$ & $\begin{array}{l}\text { T: ... Yes in fact they seem civilized or for instance polite. } \\
\text { S: As I see, only their ideas have been expressed in two words. }\end{array}$ \\
\hline
\end{tabular}

\section{Table 13}

The functions of discourse markers in groups $A, B, C$ and $D$ by teachers and students

\begin{tabular}{|c|c|c|c|c|c|c|}
\hline \multirow{9}{*}{$\begin{array}{l}\text { Textual } \\
\text { functions }\end{array}$} & Functions & Class A & Class B & Class C & Class D & Total \\
\hline & Opening markers & $10 \%$ & $8.2 \%$ & $6.3 \%$ & $9.3 \%$ & \\
\hline & Closing markers & $2.3 \%$ & $3.7 \%$ & $1 \%$ & $1 \%$ & \\
\hline & Turn taking/giving & $2.7 \%$ & $7.8 \%$ & $5.5 \%$ & $9 \%$ & \\
\hline & Fillers/ Turn keepers & $12 \%$ & $18.7 \%$ & $10.3 \%$ & $15.6 \%$ & \\
\hline & Topic switchers & $5.4 \%$ & $10 \%$ & $5.9 \%$ & $4.5 \%$ & \\
\hline & Information indicators & $46.6 \%$ & $15.7 \%$ & $28.5 \%$ & $26 \%$ & \\
\hline & $\begin{array}{l}\text { Sequence/relevance } \\
\text { markers }\end{array}$ & $6.6 \%$ & $9 \% ?$ & $24.6 \%$ & $17.7 \%$ & \\
\hline & Repair markers & $4.7 \%$ & $7.5 \%$ & $5.9 \%$ & $3.4 \%$ & \\
\hline \multirow[t]{2}{*}{$\begin{array}{l}\text { Interpersonal } \\
\text { functions }\end{array}$} & $\begin{array}{l}\text { Response/reaction } \\
\text { markers } \\
\text { (Back-channel signals) }\end{array}$ & $4.6 \%$ & $7.8 \%$ & $5.5 \%$ & $4.5 \%$ & \\
\hline & $\begin{array}{l}\text { Confirmation-seekers } \\
\text { (Face-savers) }\end{array}$ & $3.9 \%$ & $11 \%$ & $5.9 \%$ & $9.3 \%$ & \\
\hline
\end{tabular}

Table 14 represents the most and the least frequent functions of DMs applied by the teachers in the four groups. Information indicators are the most frequent functions applied by the teachers in groups A and D; but fillers are the most common ones in group B, and sequence markers in group C. Sequence markers are in the second place in groups $\mathrm{A}, \mathrm{B}$, and $\mathrm{D}$; but information indicators in group $\mathrm{C}$. The third position is taken by repair markers in group A, confirmation seekers in group B, and fillers in groups $\mathrm{C}$ and D. Turn taking markers have got the fourth place in groups $\mathrm{A}$ and $\mathrm{D}$, but interpersonal functions such as response markers and confirmation seekers in groups B and C. The fifth status belongs to closing markers and topic switchers in groups A and B, turn taking in group $\mathrm{C}$, and repair markers in group D. Confidence seekers are not applied by the teacher in group A, turn taking, closing, opening and repair markers are the subsequent functions in group B, response markers, topic switchers, opening and closing markers are the following frequent functions in group $\mathrm{C}$, and closing markers, confirmation seekers, opening, response markers, and topic switchers are in the following positions in group D. 
The frequencies and functions of discourse markers in the Iranian university EFL classroom discourse

\section{Table 14}

The functions of discourse markers in groups $A, B, C$ and $D$ applied by the teachers

\begin{tabular}{|c|c|c|c|c|c|c|}
\hline \multirow[t]{9}{*}{ Textual functions } & Functions & Class A & Class B & Class C & Class D & Total \\
\hline & Opening markers & $3.5 \%$ & $3.9 \%$ & $2 \%$ & $4.8 \%$ & \\
\hline & Closing markers & $1 \%$ & $1.9 \%$ & $1 \%$ & $0.6 \%$ & \\
\hline & Turn taking/giving & $1.9 \%$ & $5 \%$ & $4 \%$ & $7.9 \%$ & \\
\hline & Fillers/ Turn keepers & $3.5 \%$ & $12 \%$ & $7.5 \%$ & $11.4 \%$ & \\
\hline & Topic switchers & $1 \%$ & $7 \%$ & $3.5 \%$ & $2.7 \%$ & \\
\hline & Information indicators & $16.6 \%$ & $7.8 \%$ & $12 \%$ & $14.9 \%$ & \\
\hline & Sequence/relevance markers & $3.9 \%$ & $8.2 \%$ & $14.6 \%$ & $11.8 \%$ & \\
\hline & Repair markers & $3.5 \%$ & $3 \%$ & $4 \%$ & $6.5 \%$ & \\
\hline \multirow[t]{2}{*}{$\begin{array}{l}\text { Interpersonal } \\
\text { functions }\end{array}$} & $\begin{array}{l}\text { Response/reaction markers } \\
\text { (Back-channel signals) }\end{array}$ & $3.9 \%$ & $7.4 \%$ & $3.9 \%$ & $3 \%$ & \\
\hline & $\begin{array}{l}\text { Confirmation-seekers } \\
\text { (Face-savers) }\end{array}$ & $0 \%$ & $7.8 \%$ & $4.7 \%$ & $5.9 \%$ & \\
\hline
\end{tabular}

Table 15 displays the functions of DMs in the students' interaction in the samples under investigation. The highly frequent functions are information indicators in all groups. The second highly frequent ones are fillers in groups $\mathrm{A}$ and $\mathrm{B}$, and sequence markers in groups $\mathrm{C}$ and D. Turn taking markers in group A, repair markers in group $\mathrm{B}$, opening markers in groups $\mathrm{C}$ and $\mathrm{D}$ are in the third rank. The fourth grade belongs to opening markers in groups $\mathrm{A}$ and $\mathrm{B}$ and to fillers in groups $\mathrm{C}$ and $\mathrm{D}$. In the fifth grade stay topic switchers in groups $\mathrm{A}$ and $\mathrm{C}$, confirmation seekers in group B and D. In the sixth rank are placed confirmation seekers and sequence markers in group A, turn taking and topic switchers in group B, response and repair markers in group C, and response and turn taking markers in group D. Closing, repair, and response markers include the least frequent functions in group A. Closing and sequence markers are the least common functions in group B.

Confirmation seekers and turn taking are the least recurring functions in group $\mathrm{C}$ and there is no instance found for closing markers in this group. Turn taking and response markers are the least common functions in D with no instances found for closing markers. Therefore, this study revealed that out of the two functional categories of DMs, textual functions are applied more frequently by Iranian EFL teachers and learners. Since, they play a cohesive function in constructing meaning which is also reported by Ismail (2012). Then it might be due to the fact that these EFL learners did not receive enough input and education to apply interpersonal functions in their communication and are not aware of their significant contribution to the development of social relationship and the shortening of the social distance and knowledge sharing. Moreover, Persian learners' inadequate use of these functions reveals their insufficient pragmatic awareness, ineffective intercultural knowledge, and the lack of explicit instruction. So these findings are in line with Mirshamsi and Allami (2013) and Rahimi (2011) in Iranian EFL context and Simcikaite (2012) in Lithuania.

\section{Table 15}

The functions of discourse markers in groups A, B, C and D applied by the students

\begin{tabular}{|c|c|c|c|c|c|}
\hline \multirow{9}{*}{$\begin{array}{l}\text { Textual } \\
\text { functions }\end{array}$} & Functions & Class A & Class B & Class C & Class D \\
\hline & Opening markers & $6.6 \%$ & $4 \%$ & $3.9 \%$ & $4.5 \%$ \\
\hline & Closing markers & $1 \%$ & $1.8 \%$ & $0 \%$ & $0 \%$ \\
\hline & Turn taking/giving & $7 \%$ & $3 \%$ & $1 \%$ & $1 \%$ \\
\hline & Fillers/ Turn keepers & $8.6 \%$ & $7 \%$ & $2.7 \%$ & $4 \%$ \\
\hline & Topic switchers & $4 \%$ & $3 \%$ & $2 \%$ & $1.7 \%$ \\
\hline & Information indicators & $29 \%$ & $8 \%$ & $16 \%$ & $8 \%$ \\
\hline & $\begin{array}{l}\text { Sequence/relevance } \\
\text { markers }\end{array}$ & $2.7 \%$ & $1 \%$ & $9.9 \%$ & $5.9 \%$ \\
\hline & Repair markers & $1 \%$ & $4.5 \%$ & $1.5 \%$ & $0.3 \%$ \\
\hline \multirow[t]{2}{*}{$\begin{array}{l}\text { Interpersonal } \\
\text { functions }\end{array}$} & $\begin{array}{l}\text { Response/reaction markers } \\
\text { (Back-channel signals) }\end{array}$ & $0.7 \%$ & $7 \%$ & $1.5 \%$ & $1 \%$ \\
\hline & $\begin{array}{l}\text { Confirmation-seekers } \\
\text { (Face-savers) }\end{array}$ & $2.7 \%$ & $3.7 \%$ & $1 \%$ & $3 \%$ \\
\hline
\end{tabular}




\section{Conclusion}

The small number and the limited category of DMs applied in these EFL interlocutors' classroom discourse works as an awareness raiser in terms of the improper and unnatural input in EFL education, resulted in learners' being denied of access to the pragmatic use of language and implies the need for the pedagogical reformulation in discourse education. As discursive elements, DMs both signal the speakers' specific intentions about discourse content and indicate the audience expectations of the discourse in progress (Schifrin, 1978; Fraser, 2008). Consequently, teacher, learner, and, textbook variables exercise a good deal of influence on discourse structure, pattern, and pedagogy.

The results prove the evidence for the need for a comprehensive review in the Iranian EFL teacher education, teaching methodology, and in service training programs. Discussing the pragmatic aspects of DMs in authentic materials such as films and short stories, would result in raising teachers' awareness. Also, direct and indirect teaching of DMs by giving samples from native speakers' data may help both teachers and learners increase their appreciation of DMs use and function in their interactions.

In terms of the learners' variable, a modification of attitude should be motivated. In this EFL context the presupposition is that if you possess a good command of phonology, vocabulary, and grammar, you would be able to communicate competently. As a result, the subtle pragmatic aspects of DMs are ignored. So, the EFL education system can modify this outlook by raising the students' awareness and attracting their attention to the discursive and pragmatic functions of these elements by including samples from native speaker natural data. The third pedagogical implication goes with textbook. As Quan and Zheng (2012) maintain learners are not provided with adequate, appropriate, and practical input concerning the way DMs are used in real life interactions. So, to present natural pragmatic input for the teachers and the students, some texts with creative instances of DMs and their natural pragmatic functions can be included in the textbooks to meet such an end.

The major limitation of the study was lack of data triangulation. Therefore, the results justify the need for further exploration through multiple data collection procedures. Along with discovering the pitfalls, problems, and obstacles of the Iranian EFL education, this study, together with few former Iranian studies on DMs, would work as a starting point in the characterization of the features of the Iranian English. Furthermore, research on classroom interaction, specifically on DMs, may be illuminating, since the DMs' functions and the contexts they occur are so complicated. Additionally, these investigations would shed light on the versatile, comprehensive, complicated, and intricate nature of educational discourse by non-native instructors and learners.

\section{References:}

Aijmer, K. (2002). English discourse particles. Amsterdam: John Benjamins. http://dx.doi.org/10.1075/scl.10

Archakis, A. (2001). On discourse markers: Evidence from Modem Greek. Journal of Pragmatics, 5(2),

1235-1261. http://dx.doi.org/10.1016/S0378-2166(00)00054-0

Asık, A., \& Cephe, T. (2013). Discourse markers and spoken English: Nonnative use in theTurkish EFL setting. English Language Teaching, 9(12), 34-56.

Bolden, G. B. (2009). Implementing incipient actions: The discourse marker 'so' in English conversation. Journal of Pragmatics, 3(1), 974-998. http://dx.doi.org/10.1016/j.pragma.2008.10.004

Brinton, R. (1996). Pragmatic markers in English. Grammaticalization and discourse functions. New York: Mouton de Gruyter. http://dx.doi.org/10.1515/9783110907582

Castro, C. M. C. (2009). The use and functions of discourse markers in EFL classroom interaction, Profile, 11, 57-77.

Chanet, A. W. (2009). Discourse markers: A challenge for linguists and teachers. Nouveaux cahiers de linguistique française, 29(4), 23-40.

Dafouz-Milne, E. (2008). The pragmatic role of textual and interpersonal metadiscourse markers in the construction and attainment of persuasion: A cross-linguistic study of newspaper discourse, Journal of 
The frequencies and functions of discourse markers in the Iranian university EFL classroom discourse

Pragmatics, 4(3), 95-113. http://dx.doi.org/10.1016/j.pragma.2007.10.003

Djigunovic, J. M., \& Vikov, G. (2011). Acquisition of discourse markers: evidence from EFL writing. Seraz, 55, 255-278.

Duran, V. U. (2001). The discourse marker a ver (Catalan, a veure) in teacher-student interaction. Journal of Pragmatics, 2(1), 193-208. http://dx.doi.org/10.1016/S0378-2166(99)00135-6

Erman, B. (2001). Pragmatic markers revisited with a focus on you know in adult and adolescent talks. Journal of Pragmatic, 33(3), 1337-1359. http://dx.doi.org/10.1016/S0378-2166(00)00066-7

Fraser, B. (1990). An approach to discourse markers. Journal of Pragmatics, 14(2), 383-395. http://dx.doi.org/10.1016/0378-2166(90)90096-V

Fraser, B. (1999). What are discourse markers? Journal of Pragmatics, 12(3), 931-952. http://dx.doi.org/10.1016/S0378-2166(98)00101-5

Fraser, B. (2009). An account of discourse markers. International Review of Pragmatics, 14(2), 1-28.

Hellermann, J., \& Vergun, H. (2007). Language which is not taught: The discourse marker use of beginning adult learners of English. Journal of Pragmatics, 39(2), 157-179.

http://dx.doi.org/10.1016/j.pragma.2006.04.008

Ismail, H. M. (2012). Discourse markers in political speeches: Forms and functions. Journal of College of Education for Women, 23(4), 1260-1278.

Jalilifar, A. (2008). Discourse markers in composition writings: The case of Iranian learners of English as a Foreign Language. English LanguageTeaching, 1(3), 31-48.

Lenk, U. (1998). Discourse markersand global coherence in conversation. Journal of Pragmatics, 12(4), 245-257. http://dx.doi.org/10.1016/S0378-2166(98)00027-7

Liao, S. (2008). Variation in the use of discourse markers by Chinese teaching assistants in the US. Journal of Pragmatics, 11(3), 342-358.

Martínez, A. C. L. (2002).The use of discourse markers in E.F.L. learners' writing, Revista Alicantina de Estudios Ingleses, 15(4), 123-132.

Matei, M. (2010). Discourse markers as functional elements. Buletine of the Transilvania University of Brasov, $11(5), 35-53$.

Mirshamsi, A., \& Allami, H. (2013). Metadiscourse markers in the discussion/conclusion, section of Persian and English master's theses. The Journal of Teaching Language Skills, 12(5), 23-40.

Muller, S. (2004). 'Well you know that type of person': functions of well in the speech of American and German students. Journal of Pragmatics, 11(36), 1157-1182. http://dx.doi.org/10.1016/j.pragma.2004.01.008

Onodera, N. O. (2004). Japanese discourse markers: Synchronic and diachronic discourse analysis. Amsterdam: John Benjamins. http://dx.doi.org/10.1075/pbns.132

Quan, L., \& Zheng, L. (2012). A study of self-repair markers in conversation by Chinese English learners. Journal of Language Teaching and Research, 5(5), 1216-1223.

Rahimi, F., \& Riasati, J. (2012). The effect of explicit instruction of discourse markers on the quality of oral output. International Journal of Applied Linguistics \& English Literature, 11(3), 65-79.

Rahimi, M. (2011). discourse markers in argumentative and expository writing of Iranian EFL learners. World Journal of English Language, 11(2), 41-58.

Trillo, R. J. (2002). The pragmatic fossilization of discourse markers in non-native speakers of English. Journal of Pragmatics, 4(34), 769-784. http://dx.doi.org/10.1016/S0378-2166(02)00022-X

Schiffrin, D. (1987). Discourse markers. Cambridge: Cambridge University Press. http://dx.doi.org/10.1017/CBO9780511611841

Silva, A. (2006). The polysemy of discourse markers: The case of pronto in Portuguese. Journal of Pragmatics, 38(4), 2188-2205. http://dx.doi.org/10.1016/j.pragma.2006.03.009

Simcikaite, A. (2012). Spoken discourse markers in learner academic writing. Studies About Languages, 20(3), 34-49.

Taboada, M. (2006). Discourse markers as signals (or not) of rhetorical relations, Journal of Pragmatics, 38(2), 567-592. http://dx.doi.org/10.1016/j.pragma.2005.09.010

Tagliamonte, S. (2005). So who? like how? just what? Discourse markers in the conversations of young 
Nejadansari, D. \& Mohammadi, A. M.

canadians. Journal of Pragmatics, 12(4), 1896-1915. http://dx.doi.org/10.1016/j.pragma.2005.02.017

Tchizmarova, I. K. (2005). Hedging functions of the Bulgarian discourse marker 'xajde'. Journal of Pragmatics, 13(3), 1143-1163. http://dx.doi.org/10.1016/j.pragma.2005.01.003

Walsh, S. (2006). Investigating classroom discourse. London: Routledge.

Weinert, R. (1998). Discourse organization in the spoken language of L2 learners of German. Linguistische Berichte, 17(6), 459-488.

Yang, H. (2011). Investigating discourse markers in pedagogical settings:a litrature review. ARECLS, 95-10

Ying, S. (2007). An analysis of discourse markers used by non-native English learners: Its implications for teaching English as a foreign language. Retrieved

http://www.kuis.ac.jp/icci/publications/kiyo/pdfs/19/19_03.pdf 